\title{
Incomplete Markets, Labor Supply and Capital Accumulation*
}

\author{
Albert Marcet Francesc Obiols-Homs $\quad$ Philippe Weil ${ }^{\dagger}$
}

This version: October 2003

\begin{abstract}
We explore the accumulation of capital in the presence of limited insurance against idiosyncratic shocks, borrowing constraints and endogenous labor supply. In the exogenous labor supply case (e.g. Aiyagari 1994, Huggett 1997), the presence of limited insurance increases the demand for savings for precautionary reasons. As a consequence, capital and output are higher under incomplete markets. We show that if labor hours are endogenous, labor supply is likely to be lower under incomplete markets, because those agents who experience a high shock to productivity are ex post richer and they work fewer hours. In some cases, this wealth effect can overcome the "aggregate precautionary savings" and give rise to lower savings and output under incomplete markets.
\end{abstract}

KEYWORDS: Idiosyncratic shocks, incomplete markets, labor supply.

JEL Classification: D52, D58, J22

\footnotetext{
${ }^{*}$ We would like to thank I. Brocas, A. Erosa, L. Fuster, P. Legros, S. Ospina, S. Pratap, V. Quadrini, V. Ríos, J. Sadka, R. Torres, H. Uhlig, and specially M. Huggett and T. Keister for helpful comments and suggestions. Of course, all remaining errors are ours. A. Marcet acknowledges support from CREI, DGES (Spanish Ministery of Science and Technology) and DURSI (Generalitat de Catalunya). F. Obiols-Homs acknowledges financial support from the European Commission through the TMR Programme (Contract num. ERBFMBICT 961835).

${ }^{\dagger}$ A. Marcet, Universitat Pompeu Fabra, CREI and CEPR; F. Obiols-Homs, Centro de Investigación Económica, Instituto Tecnológico Autónomo de México, and P. Weil, ECARES (Université Libre de Bruxelles), I.E.P Paris, CEPR and NBER.

Address for correspondence: Francesc Obiols-Homs, CIE-Instituto Tecnológico Autónomo de México. Av. Camino Sta. Teresa 930, México D.F.-10700, E-mail: obiols@itam.mx.
} 


\section{Introduction}

A fundamental result in the precautionary savings literature is that capital market imperfections and the presence of uninsured idiosyncratic risk, leads agents to save more than they would if there were no uncertainty. ${ }^{1}$ This result holds in a wide variety of environments, including two-period and infinite-horizon setups, partial and general equilibrium models, economies with production, and when idiosyncratic shocks are i.i.d. or serially correlated. The typical comparison is between the outcome when agents receive random income draws from a given distribution, and the outcome when agents receive with certainty the expected income (or endowment) of that distribution. But this notion of precautionary saving extends to the comparison between economies with and without complete markets (i.e., competitive insurance markets). ${ }^{2}$ In particular, Aiyagari (1994) and Huggett (1997) studied dynamic economies with production and showed that capital accumulation is larger under incomplete than under complete markets. We label this effect on capital accumulation the Aiyagari-Huggett effect.

When hours worked are exogenous, an immediate implication of this effect is that output is larger under incomplete than under complete markets. This conclusion seems to give rise to an "incomplete markets puzzle", because it is contrary to the informal intuition that a more efficient allocation of resources — possibly through better developed financial intermediation-

\footnotetext{
${ }^{1}$ See for instance Leland (1968) and Sandmo (1970), and more recently, Kimball (1990), Deaton (1991), Carroll (1991), Huggett (1993) and Aiyagari (1994), among others.

${ }^{2}$ In this paper, "precautionary savings" refers to a larger accumulation of capital under uncertainty than under certainty, rather than the notion associated to the convexity of marginal utility. See Huggett and Ospina (2001) for a discussion.
} 
should not only increase welfare, but also savings, investment and output. In fact, there is an extensive theoretical and empirical literature studying the effects of financial institutions on the performance of industries and on growth rates. Just to cite an example, Levine uses data of a number of countries and reports that "there is a strong positive relationship between (...) financial indicators and (...) long run real per capita growth rates, capital accumulation and productivity growth" (Levine, 1997 pag. 706). ${ }^{3}$

In this paper we explore the implications of introducing a leisure/labor decision in dynamic, general equilibrium models. In particular, we are interested in the effect of limited insurance against idiosyncratic risks on aggregate variables, such as capital and output, when labor supply is endogenous and the idiosyncratic risk can make agents unproductive ${ }^{4}$.

Our main result is that, as long as leisure is a normal good, incomplete insurance to idiosyncratic employment shocks introduces an ex post wealth effect which reduces labor supply. The intuition is that once uncertainty is realized, employed agents under incomplete markets are richer than they would be in a complete markets world (precisely because ex-ante they could not and did not buy insurance against unemployment). ${ }^{5}$ Hence in a general equilibrium model with production, ex post wealth effects on labor supply run counter to the Aiyagari-Huggett effect, and which of these two effects

\footnotetext{
${ }^{3}$ The causality between financial development and economic growth seems to be still an unresolved question, as Levine (1997) himself emphasizes. Levine's paper is a survey of theories and empirical results about these issues with many references, thus we address the interested reader to that paper. For a more recent treatment see Smith (2002).

${ }^{4}$ Barsky, Mankiw and Zeldes (1986, pg. 680), for instance, report that “... individual incomes are highly vulnerable to disability, which includes medical, psychiatric, and other factors limiting hours of work or precluding work entirely".

${ }^{5}$ Baxter and Crucini (1995) describe a similar wealth effect under incomplete markets. They use it to explain the low consumption correlation across countries.
} 
dominates depends on the precise parameters characterizing the economy.

To our knowledge very little is known about the effects on saving and output of limited insurance against idiosyncratic risks when labor supply is endogenous. ${ }^{6}$ It seems interesting to consider endogenous labor for several reasons. First, the time spent working is an important margin that households may use to adjust income fluctuations. ${ }^{7}$ Second, abstracting from the labor/leisure decision precludes the analysis of wealth and substitution effects on labor supply. These effects are key in understanding aggregate consumption and saving (see for instance Benhabib, Rogerson and Wright (1991) and the related quantitative literature about real business cycles).

Finally, the wealth effect that we focus on has implications beyond the analysis of hours worked. Any input that is subject to uncertain productivity, has a positive wealth elasticity and is complementary with capital is likely to display similar effects on output and savings; for example, if one were to model explicitly technology adoption, entrepreneurship, human capital, etc., investment and output are likely to be smaller under incomplete markets for the same reasons that they do in our paper.

We argue in four ways that the wealth effect on labor supply lowers output

\footnotetext{
${ }^{6}$ At the theoretical level, see Flodén (1998) in the tradition of the precautionary saving literature. Related quantitative results for dynamic, general equilibrium models can be found in Ríos-Rull (1994) and Low (2002) for life cycle economies, and in Krusell and Smith (1998), Castañeda, Díaz-Giménez and Ríos-Rull (2003), and Obiols-Homs (2003), for models with infinitely lived agents. At the empirical level, the evidence regarding precautionary saving is far from clear. See for instance Carroll, Dynan and Krane (1999) and the references therein.

${ }^{7}$ There is substantial evidence of changes in the number of per capita hours worked in the U.S. over the post Korean War period: changes in per capita hours worked explain about $20 \%$ of the total variation in aggregate hours (see, for instance, Hansen (1985) and Kydland (1995)). See Abowd and Card (1989) and the references therein for studies using micro-data about the relationship between hours worked and earnings.
} 
under incomplete markets: i) we display the wealth effect in a static environment with uncertainty; ii) we show a multi-period general equilibrium example where, if the parameters are chosen so that labor demand is high and labor supply is low, output and savings are cut in half due to market incompleteness; iii) we prove analytically that, contrary to what happens when labor is exogenous, savings do not go to infinity when uncertainty is stationary and $\beta(1+r)=1$; finally, $i v)$ we report numerical simulations of multi-period models with uncertainty in all periods.

Section 2 explores a partial equilibrium static model. Section 3 analyzes a dynamic, multi-period, general equilibrium model with production, borrowing constraints, idiosyncratic shocks and incomplete insurance. ${ }^{8}$ In addition to results ii) and iii), it establishes that the interest rate in steady state is smaller than the rate of time preference, so that the capital/labor ratio is higher under incomplete markets. But if the ex post wealth effect that decreases labor supply is large enough, capital, output and savings might be lower under incomplete markets. We thus investigate numerically which effect dominates for various parameter sets in Section 4. When the parameter set is calibrated to the US economy, we find that the wealth effect dominates, and that output goes down slightly under incomplete markets. Section 5 concludes by outlining directions for further research. Appendix A gathers the proofs, and Appendix B presents computational details as well as some additional examples.

\footnotetext{
${ }^{8}$ Jappelli and Pagano (1994) study the implications for growth of market imperfections in a deterministic model with overlapping generations. They find that a borrowing limit promotes higher growth rates. In relation to this, Hernández (1991) finds that a borrowing limit has no effects on steady states in his model without uncertainty and infinitely lived, heterogeneous agents.
} 


\section{Wealth effects on labor supply in a static world}

Does the unavailability of unemployment insurance lead people to work on average more or less than when unemployment insurance is available? We first study this question in the simplest possible environment: a static economy in which a fraction of the population might be randomly unemployed.

\section{$2.1 \quad$ A simple model}

The economy consists of a continuum of ex ante identical consumers over the unit interval. Consumers have preferences $U(c, l)$ over consumption and leisure. The utility function $U$ satisfies

A1: $U: R_{+} \times[0,1] \rightarrow R_{+}$, is continuous and differentiable.

A2: $U$ is strictly increasing and strictly concave in each of its arguments, with $\lim _{c \rightarrow 0} U_{c}(c, l)=+\infty \forall l \in[0,1]$, and $\lim _{l \rightarrow 0} U_{l}(c, l)=+\infty \forall c \geq 0$

Labor supply is elastic with respect to wage (work effort would otherwise be the same under complete and incomplete markets). In addition, we require that leisure be a normal good.

All consumers are endowed with one unit of time, but are subject to exogenous idiosyncratic employment shocks (or shocks of labor productivity, like health shocks): when a consumer wakes up in the morning, she is either employed or unemployed. ${ }^{9}$ We therefore model the employment state $s$ as a random variable that takes the value 0 with probability $1-\phi$, and the value 1 with probability $\phi$. The employment probability $\phi$ is the same for all agents, but the ex post realization of the employment process is individual-

\footnotetext{
${ }^{9}$ We assume that health cannot be influenced by the consumer's actions. We thus abstract for moral hazard considerations.
} 
specific. In the aggregate, given the continuum assumption, $\phi$ also measures the fraction of the population that is employed.

Consumers receive a non-produced endowment $\Omega$ of the consumption good. This endowment is non-random, and is identical across agents. Consumers can supplement their endowment of the consumption good by devoting some of their time to work: one unit of time produces 1 unit of the consumption good in the employment state, and zero otherwise. Obviously, only employed consumers will ever choose to sacrifice leisure to work.

\subsection{Complete markets}

Suppose that the consumers' employment state can be perfectly and costlessly monitored by third parties. In that setup, competitive insurance companies can offer unemployment insurance to the consumers at the actuarially fair price $p=1-\phi$. By paying $p$ units of the consumption good to the unemployment insurance company before the shock is realized, consumers buy the right to get 1 unit of the consumption good if they end up unemployed at the end of the period, they get 0 otherwise. Letting $Q$ denote the demand for insurance, a consumer with non-produced endowment $\Omega$ solves the following program:

$$
\max _{c^{e}, c^{u}, l, Q} \phi U\left(c^{e}, l\right)+(1-\phi) U\left(c^{u}, 1\right)
$$

$$
\begin{aligned}
& \text { subject to: } \quad c^{e}+p Q=\Omega+(1-l), \quad c^{u}+p Q=\Omega+Q, \\
& c^{e}, c^{u}, Q \geq 0, \quad 0 \leq l \leq 1 .
\end{aligned}
$$


Here $c^{e}$ and $c^{u}$ denote consumption in the employment and unemployment states, and $l$ denotes leisure in the employment state (in the unemployment state leisure equals its maximum possible value 1.) Using the fact that in equilibrium $p=1-\phi$, the first-order conditions for an interior solution can be written compactly as ${ }^{10}$

$$
\begin{aligned}
& U_{c}\left(c^{e}, l\right)=U_{c}\left(c^{u}, 1\right), \\
& U_{l}\left(c^{e}, l\right)=U_{c}\left(c^{e}, l\right) .
\end{aligned}
$$

Equation (2) describes, given labor supply, the optimal insurance decision: equalize the marginal utility of consumption in the unemployment and employment states (note that this implies $c^{u}=c^{e}$ in the case with $U(\cdot, \cdot)$ separable in $c$ and $l$ ). Equation (3) characterizes, given the amount of insurance bought by the consumer, her optimal consumption and leisure decisions: equalize the wage rate (here set to 1 ) to the marginal rate of substitution between leisure and consumption $U_{l} / U_{c} \cdot{ }^{11}$ Together with the budget constraints in (1), these two-first order conditions enable us to compute the optimal $\left(c^{e}, c^{u}, l, Q\right)$ under complete markets.

We now establish a basic, and intuitive, property of the consumer's insurance decision:

Lemma 1: If leisure is a normal good, then the demand for insurance is

\footnotetext{
${ }^{10}$ The Inada conditions guarantee that $c$ and $l$ are strictly positive at the optimum. To make sure that the constraint $l \leq 1$ is not binding, we need only impose that $\Omega$ be not too large (otherwise the constraint $l \leq 1$ binds and our consumer chooses never to work, regardless of whether she is employed or not).

${ }^{11}$ One can readily verify that the implied consumption allocation coincides with the command optimum $\max _{c^{e}, c^{u}, l} U\left(c^{e}, c^{u}, l\right)$ subject to $\phi c^{e}+(1-\phi) c^{u}=l+\Omega$. The competitive equilibrium we describe is indeed a complete market equilibrium.
} 
strictly positive $(Q>0)$ in an interior solution with $l<1$.

\section{$2.3 \quad$ Incomplete markets}

An unemployed consumer under incomplete markets just consumes her endowment: $c^{u, I}=\Omega$, where variables superscripted $I$ hereafter denote incomplete market magnitudes. When she is employed, our consumer chooses consumption and work effort $\left(c^{e, I}, l^{I}\right)$ so as to maximize $U\left(c^{e, I}, l^{I}\right)$ subject to

$$
c^{e, I}=\Omega+\left(1-l^{I}\right), \quad c^{e, I} \geq 0, \quad 0 \leq l^{I} \leq 1 .
$$

The first-order condition for an interior solution is $U_{l}\left(c^{e, I}, l^{I}\right)=U_{c}\left(c^{e, I}, l^{I}\right)$. Together with the budget constraint (4), this first order condition enable us to compute the optimal $\left(c^{e, I}, l^{I}\right)$ under incomplete markets.

\subsection{Labor supply under complete and incomplete markets}

We are now ready to answer the question: does market incompleteness lead consumers to work more or less than they would under complete markets? The answer is provided by

Proposition 1: If leisure is a normal good (and for interior solutions), labor supply is lower under incomplete markets than under complete markets (i.e., $\left.l<l^{I}<1\right)$.

The intuition is clear: in the same way that you are better off ex post if your house does not burn and you have not bought fire insurance, consumers who do end up in the employed state are richer ex post under incomplete markets than under complete markets - because they did not pay an insurance 
premium for an unrealized contingency! - and they will work less under incomplete markets. ${ }^{12}$

As an example, that will be useful in section 4 to generate large effects, consider a separable utility function $U(c, l)=u(c)+n(l)$. In this case eqs. (3) and (4) imply that $l^{I}$ solves:

$$
n^{\prime}\left(l^{I}\right)=u^{\prime}\left[\Omega+\left(1-l^{I}\right)\right]
$$

On the other hand, under complete markets we have that (1) and (2) imply

$$
c^{u}=\Omega+\phi Q=\Omega-(1-\phi) Q+(1-l)=c^{e},
$$

while eqs. (1) and (3) imply

$$
n^{\prime}(l)=u^{\prime}[\Omega-(1-\phi) Q+(1-l)]
$$

Equation (6) implies $Q=1-l$. Substituting this into (7) we get

$$
n^{\prime}(l)=u^{\prime}[\Omega+\phi(1-l)]
$$

Figure 1 displays the optimal choices of an agent in the employment state, plotting both sides of equations (5) and (8). ${ }^{13}$ It is clear that $l<l^{I}$. Also, this figure suggests that the wealth effect will be big if $u$ is very concave (so

\footnotetext{
${ }^{12}$ This statement is most definitely only a statement about ex post wealth, and not ex ante, wealth. But it is ex post wealth that matters for labor supply decisions under incomplete markets.

${ }^{13} \mathrm{As}$ in the general case, interiority of the solution is guaranteed, when $u(\cdot)$ and $n(\cdot)$ satisfy Inada conditions, if $\Omega$ is not too large: $u^{\prime}(\Omega)>n^{\prime}(1)$.
} 
that $u^{\prime}$ is very steep) and/or if $n$ is close to being linear (so that $n^{\prime}$ is nearly flat). Therefore, we would expect a large wealth effect when the curvature of $n$ is much smaller than the curvature of $u$.

We conclude that when labor supply is elastic there is a fundamental economic mechanism - wealth effects in labor supply - that tends to "shrink" the size of incomplete market economies relative to complete markets. This mechanism runs counter to the "enlarging" mechanisms (precautionary and/or buffer stock saving) at the heart of the Aiyagari-Huggett effect. It is therefore natural to ask how wealth effects in labor supply may interact, in an equilibrium multi-period model.

\section{Dynamic Equilibrium}

In this section, we set up an infinite horizon model with incomplete insurance against idiosyncratic shocks. The model is inspired by Huggett (1997). We keep Huggett's notation, and draw on some of his results.

Agents maximize the expected value of discounted utility, which depends on the infinite sequence of consumption and leisure, $\left\{c_{t}, l_{t}\right\}_{t=0}^{\infty}$. Agents have identical preferences and discount factor, and maximize $E_{0} \sum_{t=0}^{\infty} \beta^{t} U\left(c_{t}, l_{t}\right)$, where the operator $E_{0}$ denotes expectation with respect to the idiosyncratic shocks conditional on information available at time 0. In addition to A1A2, we sometimes use assumption ${ }^{14}$

\footnotetext{
${ }^{14}$ Separability and homogeneity of $\mathbf{A 3}$ are sufficient to guarantee that the utility function is bounded from below, and that in equilibrium consumption and leisure are proportional (see the interior first-order condition below). These assumptions simplify the results based on dynamic programming, but the results are likely to go through for any utility function in which consumption and leisure are both normal goods. In the analytic example in Section 3.1 and in the numerical simulations in Section 4 we consider a more
} 
A3: $U(c, l)=u(c)+n(l)$ is homogeneous of degree $\gamma \in(0,1)$, with $u^{\prime}(1) \neq 0$ and $n^{\prime}(1) \neq 0$.

Each agent is endowed with both a unit of time and a labor productivity endowment (or employment shock) $s_{t} \in[0,1]$. There is only one asset (capital) which may be used as a buffer to smooth out consumption in the unemployment state. Thus, the budget constraint of the consumer reads

$$
c_{t}+k_{t} \leq\left(1+r_{t}\right) k_{t-1}+w_{t} s_{t}\left(1-l_{t}\right)
$$

where $\left(1+r_{t}\right)$ is the net interest factor from capital (i.e., the rental price of capital plus undepreciated capital) and $w_{t}$ is the wage rate. The agent also faces the constraints $0 \leq l_{t} \leq 1$ and $c_{t} \geq 0$, together with a borrowing limit in capital holdings: $k_{t} \geq \underline{B}$.

Output in period $t$ is given by an aggregate production function $f(K, H)$, assumed to satisfy

A4: $f$ displays constant returns to scale, with $f_{j} \geq 0, f_{j j}<0$.

We assume there is a single firm that maximizes profits each period taking prices as given. This firm operates the technology for production, and rents capital and labor from the agents. In equilibrium, the first order conditions of the firm are given by

$$
f_{K, t}+1-d=\left(1+r_{t}\right), \text { and } f_{H, t}=w_{t}, \quad \forall t \geq 0,
$$

where $d \in(0,1)$ is the depreciation rate of capital, and $f_{K, t}$ and $f_{H, t}$ stand respectively for the marginal productivity of capital and labor evaluated at general class of preferences. 
the optimal time $t$ input levels.

Letting $b\left(w_{t}\right) \equiv\left[n^{\prime}(1) /\left(w_{t} u^{\prime}(1)\right)\right]^{1 /(1-\gamma)}$, the first-order conditions for the leisure-labor choice of the consumer are

$$
\begin{aligned}
& \text { either }: \quad \frac{c_{t}}{l_{t}}=b\left(w_{t}\right)^{-1} s_{t} \quad \text { and } l_{t}<1 \\
& \text { or } \quad: \quad c_{t} \geq b\left(w_{t}\right)^{-1} s_{t} \quad \text { and } \quad l_{t}=1,
\end{aligned}
$$

while the first-order conditions for capital in the consumer problem are

$$
\begin{array}{rrr}
\text { either } \quad: \quad U_{c, t}=\beta\left(1+r_{t+1}\right) E_{t}\left(U_{c, t+1}\right) & \text { and } k_{t}>\underline{B} \\
\text { or } \quad: \quad U_{c, t} \geq \beta\left(1+r_{t+1}\right) E_{t}\left(U_{c, t+1}\right) & \text { and } k_{t}=\underline{B} .
\end{array}
$$

\subsection{An analytic example: one-time uncertainty}

The following example demonstrates how the wealth effect induced by idiosyncratic shocks may have a large effect in the long-run behavior of a multi-period equilibrium economy. Specifically, in the example, the ex post wealth effect always makes output and capital under incomplete markets smaller than under complete markets.

Consider two ex ante identical consumers indexed $i=1,2$ with preferences given by $U\left(c^{i}, l^{i}\right)=\log c^{i}+A \log l^{i}$. To maintain ex-ante symmetry we assume that initial wealth is equal for both agents: $k_{-1}^{1}=k_{-1}^{2}$. Assume also that the aggregate production function is Cobb-Douglas $f(K, H)=$ $K^{\alpha} H^{1-\alpha}$.

The nature of idiosyncratic employment shocks is the following. In the initial period $t=0$, agents have the same productivity $s_{0}^{1}=s_{0}^{2}=1 / 2$. In the next 
period $t=1$, a shock to productivity occurs, and one of the agents has productivity 1 and the other has productivity 0 . The agent who turns out to be (un)productive at $t=1$ remains (un)productive forever. Formally,

$$
\begin{aligned}
s_{1}^{1}+s_{1}^{2} & =1, \\
P\left(s_{1}^{1}=1\right)=P\left(s_{1}^{1}=0\right) & =0.5, \\
s_{t}^{i} & =s_{t-1}^{i} \quad \text { for all } t>1, i=1,2 .
\end{aligned}
$$

This stochastic structure could be the result of a once-and-for-all regime shift in period 1 which would permanently, but unequally, affect the labor productivity of workers in the population, making some workers more productive and others unproductive. For example, this economy may open to foreign trade at $t=1$, or a skill-biased-technological shock may occur, or a natural resource may be discovered in some region, but which part of the population will be favored by the shock is not known beforehand. ${ }^{15}$

Under complete markets, agents insure perfectly against the shock, so that in period $t=0$ they exchange bonds contingent on the realization of $s_{1}^{1}$. Symmetry implies that both agents consume the same amount in each period. In period $t=1$, after the shock is realized, the unemployed agent receives the payoff stipulated by the bond in case he ends up being unproductive. In equilibrium, this payment enables the unemployed agent to forever consume the same amount as the employed agent, even though he remains

\footnotetext{
${ }^{15}$ This stochastic and population structure differs from the one in the next subsection. The first difference is that here the shock is permanent across time. The second difference is that the shock here is perfectly positively correlated among half of the population, and perfectly negatively correlated with the other half of the population, while in the next subsection it will be independent across agents.
} 
unemployed forever. In other words, both agents consume the same amount in all periods because they insured against the possibility of (permanent) unemployment in period 0 .

Under incomplete markets, agents cannot insure perfectly. Once the shock is realized, the employed agent forever receives, in addition to his capital income, all the labor income in the economy. However, the unemployed agent receives only capital income. The employed agent is now richer than he would have been in a complete markets world, because he did not insure at time $t=0$. Since he is wealthier, he enjoys higher consumption and leisure than in the complete markets case. Hence, the total number of hours worked is less under incomplete markets than under complete markets. For some parameter values, the wealth effect of market incompleteness is so strong that it lowers long-run output and savings by half.

We now prove this formally. We use the subscript $\infty$ to indicate the longrun value of a variable, so that, for a variable $x, x_{\infty} \equiv \lim _{t \rightarrow \infty} x_{t}$. When necessary, we use subscripts $I$ and $C$ to denote incomplete and complete market variables.

\section{Proposition 2:}

a) Under complete markets both agents consume the same in all periods, so that $c_{t}^{1, C}=c_{t}^{2, C}$ for all $t \geq 0$.

Under incomplete markets the ratio of individual consumptions is constant from $t=1$ onwards, and consumption of the employed agent is larger:

$$
\frac{c_{t}^{1, I}}{c_{t}^{2, I}}=\lambda<1 \quad \text { for all } t \geq 1
$$


b) Long-run output, savings (i.e., capital), and hours worked are larger under complete markets $^{16}: Y_{\infty}^{I}<Y_{\infty}^{C}, \quad K_{\infty}^{I}<K_{\infty}^{C}, \quad H_{\infty}^{I}<H_{\infty}^{C}$.

c) Consider different parameter values. As we vary $\alpha$ :

$$
\lim _{\alpha \rightarrow 0} \frac{H_{\infty}^{I}}{H_{\infty}^{C}}, \frac{K_{\infty}^{I}}{K_{\infty}^{C}}, \frac{Y_{\infty}^{I}}{Y_{\infty}^{C}}=\frac{A+2}{2(A+1)}
$$

If, in addition, we vary $A$ :

$$
\lim _{A \rightarrow \infty, \alpha \rightarrow 0} \frac{H_{\infty}^{I}}{H_{\infty}^{C}}, \frac{K_{\infty}^{I}}{K_{\infty}^{C}}, \frac{Y_{\infty}^{I}}{Y_{\infty}^{C}}=\frac{1}{2}
$$

Part c) of this proposition says that the wealth effect is magnified when labor input is highly productive relative to capital (low $\alpha$ ) and when agents have a high preference for leisure (high $A$ ). In the language of intermediate micro, the wealth effect becomes larger when labor demand is high and labor supply is low.

In the foregoing example, there is no room for the precautionary savings effect of Aiyagari and Huggett to "enlarge" the economy under incomplete markets, since there is no uncertainty left after period $t=1$. Both effects (the shrinking of the incomplete market economy due to the wealth effect, and the Aiyagari-Huggett enlargement effect due to precautionary saving) are however present in the next model.

\footnotetext{
${ }^{16}$ Formulas for long run output, savings and employment can be found in the proof in Appendix A.
} 


\subsection{Stationary uncertainty}

We now assume a continuum of agents uniformly distributed in the unit interval. We also assume that labor productivity endowments follow a Markov chain with transition probabilities $\pi_{s^{\prime} \mid s}$. As in Section 2, with a continuum of agents there is uncertainty at the individual level but there is no aggregate uncertainty. Furthermore, we assume that idiosyncratic uncertainty follows a Markov process:

A5: $s_{t} \in S \equiv\{1,0\}$ with $\sum_{s^{\prime}} \pi_{s^{\prime} \mid s}=1$ and $\pi_{s^{\prime} \mid s}>0$ for all $s, s^{\prime} \in S$. Furthermore, $\pi_{1 \mid 1} \geq \pi_{1 \mid 0}$.

Finally, we consider the case where an agent faces a deterministic sequence of constant prices, so that $r_{t}=r$ and $w_{t}=w$ for all $t$.

\subsubsection{Characterization of decision rules}

As the utility function is unbounded above, we need to introduce an upper bound $\bar{B}$ on capital holdings to guarantee existence of the Bellman equation in the usual way. We study the agent's problem using standard dynamic programming techniques. The position at a point in time of an agent is described by $x=(k, s)$ that belong to the state space $X=[\underline{B}, \bar{B}] \times S$. Letting $v$ be the value function, the problem of an agent can be written recursively as

$$
v(x ; w, r)=\sup _{\left(c, l, k^{\prime}\right) \in \Gamma(x ; w, r)}\left\{U(c, l)+\beta E\left[v\left(x^{\prime} ; w, r\right) \mid x\right]\right\},
$$


where

$$
\begin{array}{r}
\Gamma(x ; w, r)=\left\{\left(c, l, k^{\prime}\right): c+k^{\prime} \leq w s(1-l)+(1+r) k ;\right. \\
\left.c, l \geq 0 ; l \leq 1, \text { and } \underline{B} \leq k^{\prime} \leq \bar{B}\right\} .
\end{array}
$$

The following results are an extension of Huggett $(1993,1997)$, and characterize some features of the value function and optimal decision rules (note that since $(w, 1+r)$ are constant by assumption, we simplify notation and remove them from the value function and decision rules).

Remarks: Assume A1-A5, $(w, 1+r)>0$ and $\beta(1+r) \leq 1$. Then:

R1: $v(x)$ is strictly increasing and strictly concave in $k$, and $c(x), l(x)$ and $k(x)$ are continuous in $k$.

R2: $c(x), l(x)$ and $k(x)$ are strictly positive, $c(k, s)$ is strictly increasing in $k$ and $k(k, s)$ and $l(k, 1)$ are increasing in $k$.

R3: For all $k \in[\underline{B}, \bar{B}], k(k, 0) \leq k$ (with strict inequality if $\underline{B}<k<\bar{B}$ and $\beta(1+r)<1)$.

The following Proposition characterizes more sharply the policy function $k(k, s)$.

Proposition 3: Assume A1-A5 and $w>0$. Then:

a) If $\beta(1+r) \leq 1$, for any $k \leq \bar{k}$ then $k(k, s) \leq \bar{k}$.

b) If $\beta(1+r)=1$, for any $k \geq \bar{k}$ we have $k(k, s)=k, l(k, s)=1$ and $c(k, s)=k r$.

c) If $\beta(1+r)=1$ and $k_{-1} \leq \bar{k}$, then $k_{t} \rightarrow \bar{k}$ and $l_{t} \rightarrow 1$ (a.s.).

Part c) of the Proposition exhibits the wealth effect on labor supply in 
a partial equilibrium version of the model. It says that if $\beta(1+r)=1$, then capital accumulation in the long run is bounded, unlike the case of exogenous labor where savings go to infinity (as in the papers by Aiyagari and Huggett). In our model, capital converges to $\bar{k} \equiv(b(w) r)^{-1}$, and at this level of capital the agent can maintain a consumption stream equal to $b(w)^{-1}$ without working.

The following remark follows immediately from part a) of Proposition 3:

R4: If we choose $\bar{B}>\bar{k}$ and if $k_{-1} \leq \bar{k}$, then the upper limit on capital is never binding.

This implies that the upper bound on capital that was introduced to obtain existence and uniqueness of the value function is, in fact, not binding under the conditions of the remark.

Figure 2 displays the typical shape of decisions rules for capital accumulation assuming the interest rate is equal to the rate of time preference. The Figure and part c) of Proposition 3 reflect another aspect of the wealth effect that drives the results in this paper: if $\beta(1+r)=1$, an agent will not supply any labor if she becomes sufficiently rich. At the same time, and contrary to the results by Aiyagari and Huggett, capital does not go to infinity.

\subsubsection{Stationary equilibrium}

Let $\psi$ be the aggregate state describing in any period $t$ the mass of agents in each possible state. Thus the aggregate state is a probability measure (time-invariant in a stationary equilibrium) defined on the sets $\mathcal{X}$, the Borel subsets of $X$. Call $P(x, M)$ the transition function giving the probability 
that a worker in individual state $x$ at time $t$ will have an individual state that lies in the set $M \in \mathcal{X}$ next period. ${ }^{17}$ Finally, let $K(\psi)$ and $H(\psi)$ denote the aggregate stock of capital and labor as a function of the aggregate state $\psi$. We introduce next the notion of stationary competitive equilibrium for the economy.

Definition: A stationary recursive competitive equilibrium with incomplete markets is a list of functions $(v, c, l, k, \psi, K, H)$ and a pair of prices $(w, r)$ such that:

(1) $v$ satisfies the functional equation in (15) and $c(x), l(x)$ and $k(x)$ are the associated optimal decision rules given $(w, r)$.

(2) $\left\{w_{t}, r_{t}\right\}=\{w, r\}$ satisfy (9) for all $t \geq 0$.

(3) Aggregate factor inputs are generated by decision rules of the agents:

(i) $\int_{X} k(x) d \psi=K(\psi)$,

(ii) $\int_{X} s(1-l(x)) d \psi=H(\psi)$.

(4) $\psi$ is a stationary distribution in the law of motion determined by the transition $P$ implied by the decision rules. Formally, $\psi(M)=\int_{X} P(x, M) d \psi$ for all $M$ in $\mathcal{X}$.

The following result extends Theorem 1 in Huggett (1997), and establishes the relationship between the rate of time preference and the interest rate in a stationary equilibrium.

Proposition 4: Assume A1-A5. In a stationary recursive competitive equilibrium with positive capital and labor $\beta(1+r)<1$. Therefore, $\frac{K_{\infty}^{I}}{H_{\infty}^{I}}>$ $\frac{K_{\infty}^{C}}{H_{\infty}^{C}}$.

\footnotetext{
${ }^{17}$ For a construction of the transition function, see Theorem 9.13 in Stokey and Lucas (1989, pg. 284).
} 
The intuition for this proposition is the following. From part c) of Proposition 3 , we know that if $\beta(1+r)=1$ then the capital labor ratio goes to infinity, so that (9) cannot be satisfied. The interest rate has to be smaller than the rate of time preference in order for markets to clear. At any of those steady states the distribution of wealth is uniquely determined. ${ }^{18}$ Since under complete markets $\beta(1+r)=1$, then we have that the capital labor ratio is larger under incomplete markets. But the ex post wealth effect we have described at length in this paper decreases total labor, so that total capital and output may be lower under incomplete markets depending on which effect dominates. In the following section we use numerical methods to investigate this issue in several examples.

\section{Simulations with repeated uncertainty}

The functional form for technology we use for all numerical simulations is Cobb-Douglas:

$$
f(K, H)=T K^{\alpha} H^{1-\alpha},
$$

where $T$ is a scale parameter and where $\alpha$ measures the capital output share.

\subsection{Non-separable utility}

We first use the following parametric class of utility functions:

$$
U(c, l)=\frac{\left(\left[\eta c^{-\sigma}+(1-\eta) l^{-\sigma}\right]^{-1 / \sigma}\right)^{1-\gamma}-1}{1-\gamma},
$$

\footnotetext{
${ }^{18}$ The arguments in Huggett (1993), based on Theorem 2 in Hopenhayn and Prescott (1992), can be readily applied to the endogenous labor case considered in this paper.
} 
where $\eta \in(0,1), \gamma>0$ and $-1<\sigma \neq 0$. Limiting values for $\sigma$ and $\gamma$ provide particular cases commonly used, namely

$$
\lim _{\sigma \rightarrow 0} U(c, l)=\frac{\left[c^{\eta} l^{1-\eta}\right]^{1-\gamma}-1}{1-\gamma}
$$

where the intertemporal elasticity of substitution is $1 / \gamma$ and where $\eta$ is the share parameter for leisure in the composite commodity. We also have that

$$
\lim _{\gamma \rightarrow 1}\left(\lim _{\sigma \rightarrow 0} U(c, l)\right)=\log c+A \log l
$$

the often used $\log$ utility where $A=(1-\eta) / \eta$. Thus with the functional form in (17) we can study the effect of intertemporal substitution of the composite commodity (governed by $\gamma$ ), as well as the effect of intratemporal substitution between consumption and leisure (governed by $\sigma$ ). In the benchmark calibration we fix $T=0.5$ and the usual values $\beta=0.99$, $\alpha=0.36, \eta=0.33$, and $d=0.025$ to roughly match quarterly observations of the US economy on interest rates, hours worked, and the capital output ratio.

We start by setting $\pi_{1 \mid 1}=\pi_{1 \mid 0}=0.5$, and $\underline{B}=1$. These values are somewhat arbitrary and are chosen to reduce the size of the state space and guarantee sufficient accuracy with the solution method that we use (see footnote 20 below and Appendix B for further details).

Table 1 reports aggregate capital, labor, the capital-labor ratio, output and saving rate in the competitive equilibrium with and without complete markets for $\sigma=0.01$ and several values of $\gamma$. The message of this Table is clear: 
the lower $\gamma$, the more likely it is that the wealth effect dominates and that output and savings are lower under IM. Notice that IM output is always lower for all the values of $\gamma$ reported in this table, but that IM savings are higher for the two larger values of $\gamma$ (Appendix B shows how for higher values of $\gamma$ IM output can be higher). The results in this table are motivated by the observation that the result $\beta(1+r)<1$ in a stationary equilibrium depends on having a high $\gamma$, i.e., a low intertemporal substitution.

Let us be more precise: consider a case when $U_{c, t}=1$ with probability one as is the case, for example, if $U(c, l)=c+n(l)$. Then (12) implies that the only possibility for IM equilibrium is $\beta(1+r)=1$ (unless all agents are credit constrained). Hence in this case the Aiyagari-Huggett effect disappears and the capital/labor ratio must be the same as under CM. For the utility function (17) one can expect that as $\gamma \rightarrow 0$ and $\sigma \rightarrow$ -1 the interest rate becomes closer to satisfy $\beta(1+r)=1$, since utility becomes linear at the limit. Therefore, we expect that for lower $\gamma$ 's the IM capital/labor ratio is closer to CM, as can be seen from the Table. Hence, lower $\gamma$ 's imply a smaller Aiyagari-Huggett effect and it is more likely that the wealth effect dominates.

Table 2 shows that lower values of $\sigma$ also make it more likely that the wealth effect dominates. The intuition we can offer goes along the same lines as in the previous table: lower $\sigma$ makes the utility "more linear" so that the Aiyagari-Huggett effect is smaller and there is more room for the wealth effect to dominate. 


\subsection{Separable utility}

In the examples reported in Table 3, we apply the intuition drawn from the separable utility functions considered in Section 2, and we therefore specify

$$
U(c, l)=c^{1-\gamma_{c}} /\left(1-\gamma_{c}\right)+A l^{1-\gamma_{l}} /\left(1-\gamma_{l}\right)
$$

Confirming that the static intuition of Figure 1 carries over to a dynamic stochastic setting, we observe that the wealth effect dominates by a larger amount for low curvature with respect to leisure. For the lowest curvature reported, CM capital is almost $14 \%$ larger than under IM, and CM output per capita is about $18 \%$ larger.

\subsection{Sensitivity}

Next, we return to the utility function (17) and examine the sensitivity of our results to changes in the lower bound on savings $\underline{B}$ and the probabilities $\pi$. We find that the stock of capital declines when we decrease the value of $\underline{B}$. In Table 4 we report output and capital under incomplete markets for several $\underline{B}$ in a model with $\sigma=0.2$ and $\gamma=1.001 .{ }^{19}$ The corresponding stationary allocation under complete markets is $y^{*}=0.319$ and $k^{*}=3.28$. This Table suggests that in a calibration where the Aiyagari-Huggett effect dominates, lowering $\underline{B}$ helps the economy to "complete the markets" in the sense that both the level of aggregate savings and output become closer to

\footnotetext{
${ }^{19}$ This example is fully documented in Appendix B. We choose these values of $\gamma$ and $\sigma$ because in the benchmark calibration there was "precautionary saving" and output was larger under incomplete markets (see Table 6). We obtained similar results under other parameter values.
} 
the complete markets allocation. We also find that the value of capital such that $k(k, 1)=k$ in the employment state tends to increase as we decrease the value of $\underline{B}$. For instance, the largest amount of capital with $\underline{B}=1$ is about 24.24 units, whereas with $\underline{B}=0.73$ it is about 33 units. ${ }^{20}$ Visual inspection of the typical decision rules for capital reveals that they appear to be remarkably close to the 45 degrees line. Except near the borrowing limit, there is no strong incentive to sacrifice current consumption for a larger accumulation of capital when the agent is employed, and when the agent is unemployed the stock of capital decreases very slowly.

With respect to the probabilities of employment, we find that by increasing these probabilities the differences between complete and incomplete markets tend to be smaller. For instance, in the model with $\sigma=0.2, \gamma=1.001$ and $\underline{B}=1$, we find that with $\pi_{1 \mid 1}=\pi_{1 \mid 0}=0.55$ the difference between the stock of capital under incomplete and complete markets is still positive but it reduces to 0.018 , and the difference in output reduces to 0.00011. As before, we also find that the $k(k, 1)=k$ increases with the probabilities of transition. We can offer two intuitive explanations: first, with a low probability of being employed, the premium that would be paid under complete markets for unemployment insurance would be high, so those who end up being employed under incomplete markets are very rich (compared to complete markets) and thus the wealth effect is larger. Furthermore, with a higher

\footnotetext{
${ }^{20}$ This fact makes the computation of equilibrium increasingly difficult because then the decision rule for capital in the employment state does not cross the 45 degrees line. The obvious alternative would be to increase the distance between gridpoints, at the cost of loosing accuracy. This loss is not negligible, because in general, we find that increasing the distance between points, the capital labor ratio under incomplete markets is always smaller than the one under complete markets, even for interest rates arbitrarily close (from below) to the rate of time preference.
} 
$\pi_{1 \mid 1}=\pi_{1 \mid 0}$ the serial correlation of labor income is higher, and as reported in Table II of Aiyagari (1994), the Aiyagari-Huggett effect is stronger.

The results in the previous tables suggest that it is possible to construct examples with uninsurable idiosyncratic risk and yet, there is no "precautionary saving" and output is smaller than under complete markets. In some cases (see Table 3) the results are very sizeable. In those examples, completing the markets would not only increase welfare, but also output would rise.

\subsection{Calibration}

Finally, we report the results when the employment probabilities are calibrated to the US economy with the preferences (19). In this case we assume $\pi_{1 \mid 1}=0.94$ and $\pi_{1 \mid 0}=0.91$. These values are similar to the ones in Imrohoroglu (1989) and approximately match the 93\% average employment rate (after normalizing with the participation rate) and the 13-week average duration of unemployment observed in the US economy since the Korean War (parameter values for $\beta, \eta, \delta, \alpha$ and $T$ are as before). In Table 5 we report the results for the US economy under several $\underline{B}$.

Clearly the differences between complete and incomplete markets are rather small in this Table, but we see again that capital and output under incomplete markets become smaller than under complete markets as we lower $\underline{B}$ (in spite of the large probabilities of employment). It would seem that, in this case, as we "make the markets more complete" by lowering $\underline{B}$, the Aiyagari-Huggett effect quickly becomes less important, while the wealth 
effect persists and ends up dominating. ${ }^{21}$

\section{Concluding remarks}

We have shown that low financial development may decrease output and savings if endogenous labor effort is taken into account. This occurs because, under incomplete markets, uninsured shocks create an ex post wealth effect that reduces labor supply. We have demonstrated that this wealth effect is present in various setups.

The wealth effect often (but not always) dominates, so that incomplete markets output and savings are lower. Sometimes the effect is very large, as in the analytic example of subsection 3.1 or as in Table 3. These results suggest that the effect is particularly sizeable when labor demand is large, labor supply is low, and when the curvature of the utility with respect to labor is low. In numerical examples with stationary uncertainty the effects vary substantially depending on parameter values. When employment probabilities are calibrated to the US economy, we find that the saving rate increases under incomplete markets as in Table II of Aiyagari (1994) in a model with exogenous labor, but the changes in output we report are... of the opposite sign (the wealth effect dominates when the lower bound on savings goes

\footnotetext{
${ }^{21}$ One would think that for the most interesting case of $\underline{B}=0$, the wealth effect would dominate even more strongly. But as we explain in Appendix B, it is difficult to solve this model for low $\underline{B}$ and, in particular, we cannot reach numerical solutions when $\underline{B}=0$ as we would desire. There are two computational problems in computing this equilibrium. First, the law of motion for capital is very close to the 45 degree line, and a small computational inaccuracy leads to a very different long-run average of capital. Second, the marginal utility reaches arbitrarily high values with positive probability. Any algorithm will have problems computing accurately the equilibrium under these circumstances.
} 
down). ${ }^{22}$

It is still an open question whether this decrease in output is empirically relevant. Models à la Krusell, Smith, Huggett and Aiyagari, like the one in sections 3 and 4 , are now standard in the literature of incomplete markets with idiosyncratic uncertainty. We wanted to stay as close as possible to this paradigm. These models are the heirs of the RBC literature that became standard in aggregate macroeconomics research during the 80's and 90's, but they are possibly not the best models to calibrate the wealth elasticity of labor supply. Furthermore, various generalizations or deviations from these models may display a larger effect of uncertainty on output. For example, the supply of other inputs (such as innovation, technology acquisition, human capital, managerial skills, etc.) may be more sensitive to random productivity shocks than the supply of labor, and the effect on output may be much more important if these inputs are considered. There may be other frictions that matter for savings and that have been left out of the model. Finally, Aiyagari (1995) argued that the precautionary savings effect of incomplete markets has implications over fiscal policy and that it would justify taxing capital income. Our results suggest that Aiyagari's arguments should be reevaluated.

This all leaves a lot of room for future research, but our results do suggest that equilibrium dynamic stochastic models can be used to understand the relationship between uncertainty, financial markets, and the wealth of a

\footnotetext{
${ }^{22}$ Aiyagari says "...the differences between the saving rates with and without insurance are quite small for moderate and empirically plausible values of $\sigma, \rho$, and $\mu$. ... (but in an extreme case, it) ... leads to a considerable increase in the saving rate of almost fourteen points". We also get small differences in the US calibration, but we get a difference in output of $18 \%$ in Table 3 and of $100 \%$ in the example of section 3.1 .
} 
country, since they are generally consistent with the empirical evidence that higher financial development goes along with higher output and savings. 


\section{References}

Abowd, J.M. And D. CARD, 1989. On the Covariance Structure of Earnings and Hours Changes. Econometrica, Vol. 57, 411-45.

Aiyagari, S.R., 1994. Uninsured Idiosyncratic Risk and Aggregate Saving. Quarterly Journal of Economics, Vol. 109, 659-84.

AIYAgari, S.R., 1995. Optimal Capital Income Taxation with Incomplete Markets, Borrowing Constraints and Constant Discounting. Journal of Political Economy, Vol. 103, 1158-75.

Barsky, R.B., Mankiw, G.N., And S.P. Zeldes 1986. Ricardian Consumers with Keynesian Preferences. The American Economic Review, Vol. $76,676-91$.

Baxter, M., And M.J. Crucini 1995. Business Cycles and the Asset Structure of Foreign Trade. International Economic Review, Vol. 36, 82154 .

Benhabib, J., Rogerson, R. And Wright, R., 1991. Homework in Macroeconomics: Household Production and Aggregate Fluctuations. Journal of Political Economy, Vol. 99, 1166-87.

Carroll C.D., 1994. How Does Future Income Affect Current Consumption?. Quarterly Journal of Economics, Vol. 109, 111-47

Carroll C.D., Dynan, K.E. and S.D. Krane, 1999. Unemployment Risk and Precautionary Wealth: Evidence from Households' Balance Sheets. Publication of the Federal Reserve Board, April 1999.

Castañeda, A., Díaz-Giménez, J. And J-V Ríos-Rull, 2003. Accounting for the U.S. Earnings and Wealth Inequality. Journal of Political 
Economy, Vol. 111, 818-57.

Chamberlain G. and C. Wilson, 2000. Optimal Intertemporal Consumption Under Uncertainty. Review of Economic Dynamics, Vol. 3, 36595.

Deaton, A., 1991. Saving and Liquidity Constraints. Econometrica, Vol. $59,1221-48$.

Denardo, E.V., 1967. Contraction Mappings in the Theory Underlying Dynamic Programming. SIAM Review, Vol. 9, 165-77.

FlodÉn, M., 1998. Labor Supply and Consumption under Uncertainty: A Study of Precautionary Behavior. Working Paper, Institute for International Economic Studies, Stockholm University.

Hansen, G.D., 1985. Indivisible Labor and the Business Cycle. Journal of Monetary Economics, Vol. 16, 309-27.

Hernández, A., 1991. The Dynamics of Competitive Equilibrium Allocations with Borrowing Constraints. Journal of Economic Theory, Vol. 55, $180-91$

Hopenhayn H.A. And E.C. Prescott, 1992. Stochastic Monotonicity and Stationary Distributions for Dynamic Economies. Econometrica, Vol. $60,1387-1406$.

Huggett, M., 1993. The Risk-Free Rate in Heterogeneous-Agent Incomplete Insurance Economies. Journal of Economic Dynamics and Control, Vol. 17, 953-69.

Huggett, M., 1997. The One-Sector Growth Model with Idiosyncratic Shocks: Steady States and Dynamics. Journal of Monetary Economics, Vol. 39, 385-403. 
Huggett, M. And S. Ospina, 2001. On Aggregate Precautionary Saving: When is the Third Derivative Irrelevant. Journal of Monetary Economics, Vol. 48, 373-96.

Imrohoroglu, A., 1989. Cost of Business Cycles with Indivisibilities and Liquidity Constraints. Journal of Political Economy, Vol. 97, 1364-83.

Jappelli, M. And M. Pagano, 1994. Saving, growth, and liquidity constraints. The Quarterly Journal of Economics, Vol. 109, 83-109.

Kimball, M.S., 1990. Precautionary Saving in the Small and in the Large. Econometrica, Vol. 58, 53-73.

Krusell, P. And A.A. Smith Jr., 1998. Income and Wealth Heterogeneity in the Macroeconomy. Journal of Political Economy, Vol. 106, 867-96. Kydland, F.E., 1995. Business Cycles and Aggregate Labor Market Fluctuations. Chapter 5 of Frontiers of Business Cycle Research, ed. T. Cooley. (Princeton University Press).

Leland, H., 1968. Savings and Uncertainty: The Precautionary Demand for Saving. Quarterly Journal of Economics, Vol. 82, 465-73.

Levine, R., 1997. Financial Development and Economic Growth: Views and Agenda. Journal of Economic Literature, Vol. 35, 688-726.

Low, H., 2002. Self-insurance, life-cycle labour supply and savings behavior. Research Paper, University of Cambridge.

Obiols-Homs, F., 2003. Incomplete Unemployment Insurance and Aggregate Fluctuations. Review of Economic Dynamics, Vol. 6, 602-36.

Ríos-Rull, J-V., 1994. On the Quantitative Importance of Market Completeness. Journal of Monetary Economics, Vol. 34, 463-96.

Ríos-Rull, J-V., 1995. Models with Heterogeneous Agents. Chapter 4 of 
Frontiers of Business Cycle Research, ed. T. Cooley. (Princeton University Press).

Sandmo, A., 1970. The Effect of Uncertainty on Saving Decisions. Review of Economic Studies, Vol. 37, 353-60.

Smith, B.D., 2002. Taking Intermediation Seriously. Mimeo.

Stokey, N.L. And R.E. Lucas JR., 1989. Recursive Methods in Economic Dynamics. (Harvard University Press). 


\section{Appendix A}

\section{Proof of Lemma 1}

Consider the problem $\max _{c, l} U(c, l)$ subject to $c=\omega+(1-l)$. The first-order condition for an interior solution is $U_{l}(c, l)=U_{c}(c, l)$. Manipulation of this first-order condition establishes that leisure is a normal good if and only if $\partial l / \partial \omega=\left(U_{c c}-U_{c l}\right) /\left(U_{c c}-2 U_{c l}+U_{l l}\right)>0$. Since the second-order condition for a maximum imposes that the denominator of this expression be negative, normality of leisure requires that $U_{c c}-U_{c l}<0$. Combining these results with the first-order condition (2) we have:

$$
U_{c}[\Omega+\phi Q, 1]=U_{c}[\Omega-(1-\phi) Q+(1-l), l]<U_{c}[\Omega-(1-\phi) Q, 1],
$$

Now $U_{c c}$ is strictly negative by assumption. Therefore the previous equation implies that $Q>0$.

Proof of Proposition 1

Labor supply under complete markets satisfies

$$
U_{l}[\Omega-(1-\phi) Q+(1-l), l]=U_{c}[\Omega-(1-\phi) Q+(1-l), l]
$$

while labor supply under incomplete markets solves

$$
U_{l}\left[\Omega+\left(1-l^{i}\right), l^{i}\right]=U_{c}\left[\Omega+\left(1-l^{i}\right), l^{i}\right]
$$

Comparing equation (21) with (20), we observe the incomplete and complete market labor supply decisions differ only in that consumers who do work are 
richer under incomplete markets than under complete markets, since $Q>0$, and thus, $\Omega>\Omega-(1-\phi) Q$. Hence we conclude that, if leisure is a normal good, labor supply is lower under incomplete markets than under complete markets.

\section{Proof of Proposition 2}

a) Under complete markets the solution can be inferred from a planner's problem. Since agents are ex-ante identical they each receive the same weight in the planner's problem so the complete markets solution can be found by maximizing $E_{0} \sum \beta^{t}\left[U\left(c_{t}^{1}, l_{t}^{1}\right)+U\left(c_{t}^{2}, l_{t}^{2}\right)\right]$ subject to feasibility. For the loglog utility function of this example, the FOC of this planner's problem imply consumption of both agents is the same.

Under incomplete markets, since for $t>1$ there is no randomness we have $E_{t}\left(U_{c, t+1}^{i}\right)=U_{c, t+1}^{i}$ for all $t>1$. Dividing (12) for $i=1$ by the equation for $i=2$ for each $t>0$ proves the equality in (14).

To prove the inequality in (14), substitute forward in the budget constraint of agent $i$ from period $t=1$ onwards to obtain the usual (now deterministic) expression of the constraint in terms of discounted present value

$$
k_{0}^{i, I} r_{1}^{I}+\sum_{j=0}^{\infty}\left(\prod_{\tau=1}^{j}\left(1+r_{\tau}^{I}\right)\right)^{-1} s_{1}^{i} w_{1+j}^{I}\left(1-l_{1+j}^{i, I}\right)=\sum_{j=0}^{\infty}\left(\prod_{\tau=1}^{j}\left(1+r_{\tau}^{I}\right)\right)^{-1} c_{1+j}^{i, I}
$$

It is clear that the discounted value of labor income of the unemployed agent is zero but it is positive for the employed agent. Since both agents are symmetric at $t=0$ they choose $k_{0}^{1, I}=k_{0}^{2, I}$. Therefore, the left hand side of (22) is strictly larger for the employed agent, the right hand side must be 
larger for the employed agent, so that consumption of the employed agent must be higher and $\lambda<1$.

Now we prove part b). Under $\mathbf{A} 4$ we know that in the long run the model converges to the steady state. The steady state can be found in a standard way to obtain:

$$
\frac{K_{\infty}^{I}}{H_{\infty}^{I}}=\frac{K_{\infty}^{C}}{H_{\infty}^{C}}=\left[\left(\beta^{-1}-1+d\right) \alpha^{-1}\right]^{\frac{1}{\alpha-1}}
$$

To obtain a formula for $\frac{H_{\infty}^{I}}{H_{\infty}^{C}}$ notice that the FOC for the consumption-leisure decision and (9) give

$$
\frac{c_{\infty}^{e, I}}{l_{\infty}^{e, I}}=\frac{c_{\infty}^{e, C}}{l_{\infty}^{e, C}}=\left[\frac{K_{\infty}^{I}}{H_{\infty}^{I}}\right]^{\alpha} \frac{1-\alpha}{A},
$$

and using part a) the feasibility condition gives

$$
\begin{gathered}
(1+\lambda) c_{\infty}^{e, I}+d K_{\infty}^{I}=\left(K_{\infty}^{I}\right)^{\alpha}\left(H_{\infty}^{I}\right)^{1-\alpha}, \\
2 c_{\infty}^{e, C}+d K_{\infty}^{C}=\left(K_{\infty}^{C}\right)^{\alpha}\left(H_{\infty}^{C}\right)^{1-\alpha} .
\end{gathered}
$$

Combining these three equations and (23) we have

$$
\begin{gathered}
(1+\lambda)\left[\frac{K_{\infty}^{I}}{H_{\infty}^{I}}\right]^{\alpha} \frac{1-\alpha}{A}\left(1-H_{\infty}^{I}\right)+d \frac{K_{\infty}^{I}}{H_{\infty}^{I}} H_{\infty}^{I}=\left[\frac{K_{\infty}^{I}}{H_{\infty}^{I}}\right]^{\alpha} H_{\infty}^{I}, \\
2\left[\frac{K_{\infty}^{I}}{H_{\infty}^{I}}\right]^{\alpha} \frac{1-\alpha}{A}\left(1-H_{\infty}^{C}\right)+d \frac{K_{\infty}^{I}}{H_{\infty}^{I}} H_{\infty}^{C}=\left[\frac{K_{\infty}^{I}}{H_{\infty}^{I}}\right]^{\alpha} H_{\infty}^{C} .
\end{gathered}
$$


Solving for the $H$ 's and rearranging gives

$$
\frac{H_{\infty}^{I}}{H_{\infty}^{C}}=\frac{1+\lambda}{2} \frac{A\left(1-\frac{d \alpha}{\beta^{-1}-1+d}\right)+(1-\alpha) 2}{A\left(1-\frac{d \alpha}{\beta^{-1}-1+d}\right)+(1-\alpha)(1+\lambda)}
$$

Now, notice that

$$
r_{1} k_{0}^{1, I}=\alpha\left(\frac{K_{0}^{I}}{H_{1}^{I}}\right)^{\alpha-1} \quad k_{0}^{1, I} \leq \frac{\alpha}{2}\left(K_{0}^{I}\right)^{\alpha} \leq \alpha\left(K_{-1}^{\alpha}+(1-d) K_{-1}\right)^{\alpha}
$$

where the first equality is from the equilibrium formula for $r$, the following inequality follows from $k_{0}^{1}=k_{0}^{2}$ and $H \leq 1$, and the last inequality from the feasibility constraint. Therefore, taking the limit in the right of the above equation, if $\alpha \rightarrow 0$ then $r_{1} k_{0}^{1, I} \rightarrow 0$. Hence, if $\alpha \rightarrow 0$ then (22) implies that $c_{t}^{U, I} \rightarrow 0$ and $\lambda \rightarrow 0$. Taking the limit in (24) as $\alpha, \lambda \rightarrow 0$ implies part b). Part c) of the proposition follows immediately.

\section{Proof of Remarks}

The assumptions on $U(c)$ and $n(l)$ imply that the utility function is bounded below by 0 . Since capital is bounded above by $\bar{B}$, by standard arguments there exists a unique function $v(x)$ in the space of bounded continuous functions on $X$ satisfying the functional equation (15), and there also exist the corresponding optimal decision rules (see respectively Theorem 9.6 in Stokey and Lucas (1989) and Corollary 2 in Denardo (1967)). The proofs for $R 1$ to R3 use these facts and follow from the same arguments as in Huggett 1993 (p. 964-68) and 1997 (p. 399-400).

Proof of Proposition 3 
To prove a), First consider the case $r>0$. Following the proof of Theorem 1 in Huggett (1993), under A1-A4 and $k \in[\underline{B}, \bar{B}]$ it can be shown by induction that $v^{\prime}(k, 1) \leq v^{\prime}(k, 0)$, i.e., $c(k, 0) \leq c(k, 1)$. For an agent in the unemployment state, $R 3$ and the budget constraint imply that $c(\bar{k}, 0) \geq b(w)^{-1}$. Since $c(\bar{k}, 0) \leq c(\bar{k}, 1)$, then the FONC with respect to leisure implies $l(\bar{k}, 1)=1$. Therefore $k(\bar{k}, 1) \leq \bar{k}$.

$r \leq 0$ : Take $k_{1}<k_{2}$, thus $c\left(k_{1}, 1\right)<c\left(k_{2}, 1\right)$. The budget constraint of an employed agent implies that $w\left(1-l\left(k_{1}, 1\right)\right)+(1+r) k_{1}-k\left(k_{1}, 1\right)<$ $w\left(1-l\left(k_{2}, 1\right)\right)+(1+r) k_{2}-k\left(k_{2}, 1\right)$, thus $k\left(k_{2}, 1\right)-k\left(k_{1}, 1\right)<(1+r)\left(k_{2}-\right.$ $\left.k_{1}\right)+w\left(l\left(k_{1}, 1\right)-l\left(k_{2}, 1\right)\right)$. Since leisure is also strictly increasing in the level of capital, it follows that $\left(k\left(k_{2}, 1\right)-k\left(k_{1}, 1\right)\right) /\left(k_{2}-k_{1}\right)<1$.

To prove b), consider the optimal choice of $\left\{c_{t}, l_{t}, k_{t}\right\}$ in the consumer problem when the initial condition satisfies $k_{-1} \geq \bar{k}$. It is immediate to check that the allocation $\left\{\widetilde{c}_{t}, \widetilde{l}_{t}, \widetilde{k}_{t}\right\}=\left\{k_{-1} r, 1, k_{-1}\right\}$ satisfies all first order conditions for any $s$. The FOC for labor are satisfied because $\widetilde{c}_{t}=k_{-1} r \geq \bar{k} r=b(w)^{-1}$ and the FOC for capital are also satisfied because $U_{c, t}$ is constant. Since the problem is concave the first order conditions are sufficient for an optimum. Since the policy function gives the optimum, we have that for $k_{-1} \geq \bar{k}$ it must hold that $c\left(k_{-1}, s\right)=\widetilde{c}_{0}=k_{-1} r, l\left(k_{-1}, s\right)=\widetilde{l}_{0}=1$, and $k\left(k_{-1}, s\right)=\widetilde{k}_{0}=k_{-1}$ To prove $\mathrm{c}$ ), notice first that part a) implies that $k_{t} \leq \bar{k}$ for all $t$, and $\mathrm{R} 2$ together with part b) imply that $c_{t} \leq c(\bar{k}, s)=\bar{k} r$ so that consumption is bounded a.s. Notice that the FOC for capital (12) and (13) imply that $u_{c, t} \geq$ $E_{t}\left(u_{c, t+1}\right)$ a.s., so that $u_{c, t}$ is a super-martingale. Since $u_{c, t}$ is bounded below by $u^{\prime}(\bar{k} r)$ the martingale convergence theorem applies and it implies that $u_{c, t}$ converges a.s. to a random variable. Assume, towards a contradiction, that 
$u_{c, t}$ converged to a value strictly larger than $u^{\prime}(\bar{k} r)$, consumption would converge to a point $c^{l}<b(w)^{-1}$ so that we would have an interior solution for the consumption-leisure decision of employed agents and (10) applies if $s_{t}=1$. Under these circumstances labor income would converge to $w(1-$ $\left.b(w) c^{l}\right) s_{t}$, which is a non-degenerate i.i.d. random variable with positive variance. The arguments in Chamberlain and Wilson (2000) imply that the lower or upper bounds on capital will be violated with positive probability in this case, to that it is impossible for $u_{c, t}$ to converge to a value strictly larger than $u^{\prime}(\bar{k} r)$. Therefore, the only possibility is that $u_{c, t}$ converges to $u^{\prime}(\bar{k} r)$ and, since $u^{\prime}$ is invertible, consumption converges to $b(w)^{-1}$. The budget constraint implies that $k_{t}$ must converge to $\bar{k}$.

Proof of Proposition 4

By the usual arguments (e.g., Aiyagari 1994, Chamberlain and Wilson 2000), if $\beta(1+r)>1$ consumption converges to infinity which is unfeasible. Proposition $3 \mathrm{c}$ ) implies that if $\beta(1+r)=1$ then capital is bounded but labor goes to zero for each agent. Therefore, the aggregate capital/labor ratio goes to infinity for each initial distribution of wealth, which is incompatible with equilibrium and (9). Therefore, the only possibility for existence of a stationary equilibrium under incomplete markets is that $\beta(1+r)<1$. Since $\beta(1+r)=1$ under complete markets, then we have that the capital labor ratio must be larger for incomplete markets if (9) is to be satisfied. 


\section{Appendix B}

The method we use to solve for an equilibrium of incomplete markets involves three iterative steps: 1) given an interest rate we determine the corresponding capital labor ratio and wage rate (this is always possible with a constant returns to scale technology as input prices in equilibrium depend only on the capital labor ratio), and we find decision rules that solves an agent's problem; 2) given these rules, we simulate them over a large number of periods and we find the implied capital labor ratio; 3) given the new capital labor ratio, update input prices using the bisection method as explained in Aiyagari (1994). The procedure continues until the interest rate implied by the supply side of capital/labor is approximately equal to the interest rate in the demand side.

Step one is based on dynamic programming and follows Huggett (1993). The algorithm finds decision rules for capital and leisure by approximating the derivative of the value function with piece-wise linear functions on a grid of points for state variables. This method allows for choosing capital levels not in the grid. In practice we use a grid of 1,500 points for capital, where the distance between the first 10 points is 0.005 and the distance between the remaining points is between 0.019 and 0.022 (we make sure that the decision rule for capital in the employment state, $k(k, 1)$, crosses the 45 degrees line). In our application we approximate decision rules up to the $10^{-7}$ decimal point. We use 500,000 time periods in the integration by simulation of decision rules, and equilibrium interest rates vary less than $0.0005 \%$, thus the equilibrium capital labor ratio varies less than 0.003 . The 
equilibrium with complete markets can be determined directly using the first order and feasibility conditions which deliver a non linear equation in one unknown. We solve this equation using the Newton method.

We have detected some inaccuracies in the method used to compute the examples, mainly, that with a large distance between grid-points we tend to underestimate the stock of capital. In the examples reported in the text we try to minimize these inaccuracies by using a large number of points and a small distance between them. The problem with this approach is that there are calibrations for which we cannot compute an accurate equilibrium, for instance, with large $\sigma$, large probabilities of transition, and small borrowing limits. In those cases the $k(k, 1)=k$ in the employment state becomes very large and the decision rule does not cross the 45 degrees line. Furthermore, increasing the distance between points in general does not help because then, the capital labor ratio under incomplete markets is always smaller than the one under complete markets, even for interest rates arbitrarily close (from below) to the rate of time preference. The case of small $\gamma$ is also difficult to solve because then the right and left hand side of the Euler Equation do not cross.

In the second step of the computations we have tried two approaches with similar, though not identical, results. The first one is to find the ergodic distribution of agents over states and use it to integrate decision rules for capital and labor (Huggett (1993) describes this method in detail). The second procedure integrates decision rules by simulation exploiting ergodicity. In some experiments we find that the first approach produces slightly smaller amounts of capital and slightly larger capital labor ratios. Precisely 
for this reason we choose to use the second approach, for which we find essentially the same results with 300,000 and 500,000 time periods.

Finally, the bisection method used to update the interest rate does not always converge, as supply curves of capital and labor shift when prices change. The reason is that the distribution of agents over states depends on prices. However, the method is very useful to bracket a narrow interval from which we can "hunt" the approximate market clearing interest rate. The following Tables 6 to 7 report additional examples corresponding to the general class of preferences in (17). 
Table 1: Equilibrium allocations with several $\gamma$.

\begin{tabular}{|l|c|c|c|c|c|c|c|c|}
\hline \hline$\gamma=$ & \multicolumn{2}{|c|}{1.01} & \multicolumn{2}{c|}{1.1} & \multicolumn{2}{c|}{1.2} & \multicolumn{2}{c|}{1.3} \\
\hline \hline & C.M. & I.M. & C.M. & I.M. & C.M. & I.M. & C.M. & I.M. \\
\hline \hline$k$ & 2.986 & 2.966 & 2.958 & 2.952 & 2.93 & 2.931 & 2.905 & 2.912 \\
$h$ & 0.232 & 0.23 & 0.23 & 0.228 & 0.227 & 0.226 & 0.225 & 0.224 \\
$k / h$ & 12.861 & 12.895 & 12.861 & 12.943 & 12.861 & 12.967 & 12.861 & 12.985 \\
$y$ & 0.291 & 0.288 & 0.288 & 0.286 & 0.285 & 0.284 & 0.283 & 0.282 \\
$s r$ & 0.256 & 0.256 & 0.256 & 0.257 & 0.256 & 0.257 & 0.256 & 0.257 \\
\hline \hline
\end{tabular}

Note: Equilibrium under complete markets (C.M.) and incomplete markets (I.M.). In all experiments $\underline{B}=1, \sigma=0.01$ and $\pi_{1 \mid 1}=\pi_{1 \mid 0}=0.5$.

Table 2: Equilibrium allocations with several $\sigma$.

\begin{tabular}{|l|c|c|c|c|c|c|c|c|}
\hline \hline$\sigma=$ & \multicolumn{2}{|c|}{0.0001} & \multicolumn{2}{c|}{0.001} & \multicolumn{2}{c|}{0.01} & \multicolumn{2}{c|}{0.1} \\
\hline \hline & C.M. & I.M. & C.M. & I.M. & C.M. & I.M. & C.M. & I.M. \\
\hline \hline$k$ & 2.972 & 2.952 & 2.973 & 2.954 & 2.989 & 2.97 & 3.137 & 3.172 \\
$h$ & 0.231 & 0.228 & 0.231 & 0.229 & 0.232 & 0.23 & 0.243 & 0.242 \\
$k / h$ & 12.861 & 12.894 & 12.861 & 12.896 & 12.861 & 12.897 & 12.861 & 13.105 \\
$y$ & 0.289 & 0.287 & 0.289 & 0.287 & 0.291 & 0.289 & 0.305 & 0.305 \\
$s r$ & 0.256 & 0.256 & 0.256 & 0.256 & 0.256 & 0.256 & 0.256 & 0.259 \\
\hline \hline
\end{tabular}

Note: same as Table 1 except $\gamma=1.001$ and $\sigma$ varies.

Table 3: Equilibrium allocations.

\begin{tabular}{|l|c|c|c|c|}
\hline \hline$\gamma_{l}=$ & \multicolumn{2}{|c|}{0.7} & \multicolumn{2}{c|}{0.5} \\
\hline \hline & C.M. & I.M. & C.M. & I.M. \\
\hline \hline$k$ & 3.582 & 3.305 & 3.921 & 3.448 \\
$h$ & 0.278 & 0.245 & 0.304 & 0.253 \\
$k / h$ & 12.861 & 13.475 & 12.861 & 13.579 \\
$y$ & 0.349 & 0.312 & 0.382 & 0.324 \\
$s r$ & 0.256 & 0.264 & 0.256 & 0.265 \\
\hline \hline
\end{tabular}

Note: same as Table 1 except $\gamma_{c}=1.1$. 
Table 4: Equilibrium allocations with several $\underline{B}$.

\begin{tabular}{|c|c|c|c|c|c|c|c|c|}
\hline \hline$\underline{B}=$ & \multicolumn{2}{|c|}{1} & \multicolumn{2}{c|}{.9} & \multicolumn{2}{c|}{.8} & \multicolumn{2}{c|}{.73} \\
\hline \hline & $y$ & $k$ & $y$ & $k$ & $y$ & $k$ & $y$ & $k$ \\
\hline \hline I.M. & 0.322 & 3.388 & 0.321 & 3.357 & 0.319 & 3.312 & 0.318 & 3.291 \\
\hline \hline
\end{tabular}

Note: same as Table $1 \sigma=0.2$ and $\gamma=1.001$.

Table 5: Equilibrium allocations for the US economy.

\begin{tabular}{|l|ccccc|}
\hline \hline & $k$ & $h$ & $k / h$ & $y$ & $s r$ \\
\hline \hline C.M. & 3.7944 & 0.295 & 12.8617 & 0.3699 & 0.2564 \\
\hline \hline I.M. $(\underline{B}=2.7)$ & 3.7973 & 0.2949 & 12.876 & 0.3699 & 0.2565 \\
\hline I.M. $(\underline{B}=2.67)$ & 3.7957 & 0.2949 & 12.8711 & 0.3699 & 0.2565 \\
\hline I.M. $(\underline{B}=2.64)$ & 3.7936 & 0.2949 & 12.8639 & 0.3698 & 0.2564 \\
\hline I.M. $(\underline{B}=2.61)$ & 3.793 & 0.2948 & 12.8627 & 0.3698 & 0.2564 \\
\hline \hline
\end{tabular}

Equilibrium for the log utility case with $\pi_{1 \mid 1}=0.94$ and $\pi_{1 \mid 0}=0.91$, and several $\underline{B}$.

Table 6: Equilibrium allocations with several $\sigma$ (cont. Table 1).

\begin{tabular}{|l|c|c|c|c|c|c|c|c|}
\hline \hline$\sigma=$ & \multicolumn{2}{|c|}{0.2} & \multicolumn{2}{c|}{0.3} & \multicolumn{2}{c|}{0.4} & \multicolumn{2}{c|}{0.5} \\
\hline \hline & C.M. & I.M. & C.M. & I.M. & C.M. & I.M. & C.M. & I.M. \\
\hline \hline$k$ & 3.28 & 3.388 & 3.405 & 3.456 & 3.514 & 3.628 & 3.61 & 3.708 \\
$h$ & 0.255 & 0.253 & 0.264 & 0.262 & 0.273 & 0.271 & 0.28 & 0.278 \\
$k / h$ & 12.861 & 13.366 & 12.861 & 13.161 & 12.861 & 13.38 & 12.861 & 13.32 \\
$y$ & 0.319 & 0.322 & 0.332 & 0.332 & 0.342 & 0.344 & 0.352 & 0.353 \\
$s r$ & 0.256 & 0.262 & 0.256 & 0.26 & 0.256 & 0.262 & 0.256 & 0.262 \\
\hline \hline
\end{tabular}

Table 7: Equilibrium allocations with several $\gamma$ (cont. Table 2).

\begin{tabular}{|l|c|c|c|c|c|c|c|c|}
\hline \hline$\gamma=$ & \multicolumn{2}{|c|}{1.4} & \multicolumn{2}{c|}{1.5} & \multicolumn{2}{c|}{1.6} & \multicolumn{2}{c|}{1.7} \\
\hline \hline & C.M. & I.M. & C.M. & I.M. & C.M. & I.M. & C.M. & I.M. \\
\hline \hline$k$ & 2.882 & 2.862 & 2.862 & 2.878 & 2.843 & 2.855 & 2.825 & 2.855 \\
$h$ & 0.224 & 0.222 & 0.222 & 0.221 & 0.221 & 0.219 & 0.219 & 0.218 \\
$k / h$ & 12.861 & 12.872 & 12.861 & 13.015 & 12.861 & 12.99 & 12.861 & 13.064 \\
$y$ & 0.281 & 0.278 & 0.279 & 0.278 & 0.277 & 0.276 & 0.275 & 0.275 \\
$s r$ & 0.256 & 0.256 & 0.256 & 0.258 & 0.256 & 0.258 & 0.256 & 0.258 \\
\hline \hline
\end{tabular}




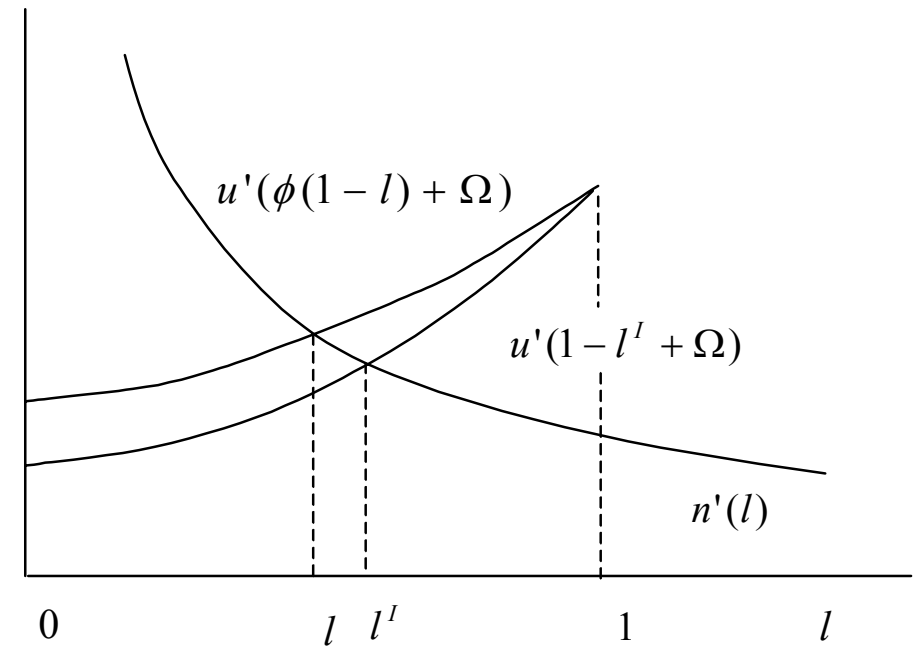

Figure 1: An example where preferences are separable in consumption and leisure.

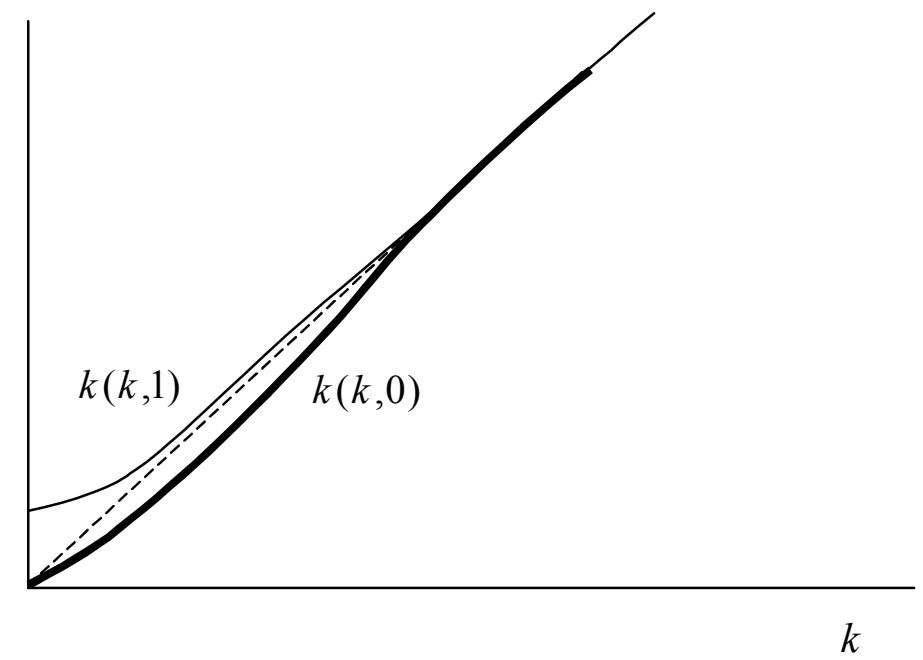

Figure 2: Decision rules for capital in the employment state (thin line) and in the unemployment state (thick line) when the interest rate equals the rate of time preference. 